Volume 9, No.4, July - August 2020

International Journal of Advanced Trends in Computer Science and Engineering

Available Online at http://www.warse.org/IJATCSE/static/pdf/file/ijatcse367942020.pdf

https://doi.org/10.30534/ijatcse/2020/367942020

\title{
Cloud-based CRM systems: Analysis of Technologies and Opportunities to Communicate with Consumers
}

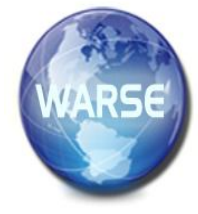

\author{
Deni Dokkaevich Saydulaev ${ }^{1}$, Valery V. Bezpalov ${ }^{2}$, Tatyana Vladimirovna Deeva ${ }^{3}$ \\ ${ }^{1}$ Chechen State University, Grozny, Russia \\ ${ }^{2}$ Plekhanov Russian University of Economics, Moscow, Russia \\ ${ }^{3}$ Market Economy Institute of RAS (MEI RAS), Moscow, Russia
}

\begin{abstract}
Modern conditions of establishment of efficient relations with customers require for ever increasing amount of reliable, timely, and complete information. Adoption of managerial decisions, maintaining efficient business processes are more and more based on optimum information system of customer relationship management (CRM). Many authors have described and highlighted different types of such systems, nevertheless, generalized and extended classification is still unavailable. This article substantiates the importance of cloud-based CRM systems; the features of cloud-based CRM systems in the course of communications with customers are discussed. On the basis of expert survey, the most popular cloud-based CRM systems are compared, their main properties and distinctive features are presented.
\end{abstract}

Key words: CRM system, cloud services, cloud-based CRM systems, communications with consumers.

\section{INTRODUCTION}

Information technologies play dual role in establishment of customer relationship management (CRM) [1,2]. On the one hand, individual approach to interrelationship with customers requires for arrangement of information about internal business projects and facilitates rapid search for necessary data in order to adopt decisions during sales and aftersales customer service. On the other hand, as a consequence of such interaction with customers, a data array is accumulated, which after adequate analysis and interpretation could be valuable to improve quality of commodities and services, or internal business processes and even for improvement of business strategy $[3,4]$.

Modern information CRM systems generate knowledge base with the opportunity to develop new commodities and services and to improve the existing ones, thus improving market positions of companies and their financial results [5-7]. Evolution and development of CRM related software lead to the concept, according to which companies in their

relationships with customers should focus on their demands $[8,9]$.

Batter [10] believes that the relationships between customer and company should not terminate at sales, the customer should obtain appropriate warranty and service. All actions of the company should be oriented at formation of customer loyalty, which would lead to higher chance of another visit to the company to satisfy the customer demands.

Nowadays the number of companies using CRM systems increases. This is stipulated by the fact that automated CRM systems propose numerous serious advantages, which support the relevance of such systems [11-13].

According to D.M. Lambert [14], CRM system is comprised of applications for automated sales, automated marketing, servicing customers, and customer support management, such as automated e-mail.

Analysis of the works [15-20] allowed to systematize the tasks, which could be solved by the CRM systems summarized in Table 1. 
Deni Dokkaevich Saydulaev et al., International Journal of Advanced Trends in Computer Science and Engineering, 9(4), July - August 2020, 6717 - 6723

Table 1: Tasks fulfilled by operational, analytical, and collaborative CRM systems

\begin{tabular}{|c|c|}
\hline Types of CRM systems & Tasks fulfilled by CRM system \\
\hline Operational & $\begin{array}{l}\text { - generation of databases; } \\
\text { - automation of phone trades and customer services; } \\
\text { - generation of interrelation history for each customer; } \\
\text { - online access to information regarding each customer; } \\
\text { - improvement of business processes with orientation to customer. }\end{array}$ \\
\hline Analytical & $\begin{array}{l}\text { - search, accumulation, and arrangement of databases on customers and interrelations with them; } \\
\text { - synchronization of various data arrays; } \\
\text { - analysis and interpretation of statistic regularities to improve strategy of trading and servicing } \\
\text { customers, etc.; } \\
\text { - decision support systems; } \\
\text { - developing mechanisms to increase sales by stimulation, interest and loyalty of consumers }\end{array}$ \\
\hline Collaborative & $\begin{array}{l}\text { - attraction of customers to development or improvement of commodities and services; } \\
\text { - arrangement of customer online self-service; } \\
\text { - interactive access to information of various functional departments; } \\
\text { - development of customer contacts with company via various channels (phone, online, etc.); } \\
\text { - integration of various information services and infrastructure, provision of interaction among } \\
\text { customers, company, and its employees. }\end{array}$ \\
\hline
\end{tabular}

According to the researchers [21, 22], correct and efficient operation of CRM system should be based on certain principles:

1. Identification. Determination of consumers would allow to understand purchasing model of each individual customer.

2. Interactivity. Automated proposal of assistance, prepared commodities, data, service to customers, which can be valuable for a specific customer.

3. Differentiation. Individual approach to each consumer should be determined on the basis of systems of values and needs of each consumer.

4. Tracking. In order to better understand consumers, it is required to fix all transactions of each customer.

5. Personalization. Development of sets of commodities, information units, and service components, which can be used for development of commodities and services adapted to demands of certain consumers.

It is believed [23] that selection of CRM system should be aimed at specific conditions and features of company business as well as at compliance of its cost with budget and business demands. If all these criteria are met, then the system will significantly facilitate company business increasing its efficiency.

In the course of development of online technologies, it became possible to host software on web server of developer or provider, access to it is presented to the user company on an online rental basis. This model is known as SaaS (Software as a Service), it becomes more and more popular in global software market, including the CRM systems [24, 25].

On the basis of the data in [26-28], the following advantages of SaaS model were revealed: savings due to software license purchase and formation of IT structure; the service provider agrees to install, configure, and to maintain the software; rapid start of the service; integration of SaaS and social networks, such as Facebook and Twitter.

Implementation of control system of customer relationships based on SaaS model is reasonable, then the software meets the requirements of functionality, and integration with other information subsystems is not required [29]. The key restrictions are complexity of existing business processes, necessity to integrate software into information corporate system, high requirements to operation rate and guaranteed access to applications [30].

This article is aimed at analysis of technologies and opportunities of communications with customers using cloud-based CRM systems.

The study hypothesis is as follows: cloud-based CRM system allows to automate communications with customer and processing of customer requests, which positively impacts implementation of customer-oriented strategy and promotes increase in company profit.

It can be concluded that the formulated aim was achieved.

\section{METHODS}

General scientific methods were used to solve the formulated problems:

a) theoretical: analysis of scientific publications devoted to the subject in order to analyze the existing techniques and opportunities to communicate with customers using cloud-based CRM systems, and to generalize domestic and foreign experience of operation with cloud-based CRM systems;

b) empirical: expert online survey to compare the available cloud-based CRM systems. 
The survey was performed among 40 experts involved in implementation of cloud-based CRM systems in Russian companies, i.e. it could be assumed that these persons were well acquainted with the modern trends of development in this sphere.

The experts aimed at determination of the most popular cloud-based CRM systems in Russia and at their comparison in terms of the highlighted criteria.

The following criteria were used for comparison: integration with accounting systems (external resources), interface usability (should be intuitive and informative at the same time), telephony and capability to record phone conversations, calendar (availability of services to plan meetings, communications among customers), data import, acquisition of analytical data and report generation, online support in real time, availability of searching and marketing, transparency of CRM system, storage of data and history of communications with customers, availability of own cloud, availability of B2B services, monitoring manager's operation, reduction of transaction time, automation of business processes, cross-platform software, integration with social networks, Telegram and other messengers.

\section{RESULTS}

The following cloud-based CRM systems were determined by the experts as the most popular: Bitrix24, amoCRM, Terrasoft, SugarCRM, Dynamics CRM.

These CRM systems were compared on the basis of expert survey (Table 2).

Table 2: Comparison of cloud-based CRM systems

\begin{tabular}{|c|c|c|c|c|c|}
\hline Criteria & Bitrix24 & amoCRM & Terrasoft & SugarCRM & Dynamics CRM \\
\hline Integration with external systems & + & + & + & + & + \\
\hline Cloud availability & + & - & - & - & + \\
\hline Interface usability & ++ & +++ & ++ & ++ & +++ \\
\hline Telephony & + & + & + & + & + \\
\hline Recording phone conversations & + & + & + & - & + \\
\hline Calendar & + & + & + & + & + \\
\hline Analysis and report generation & + & + & + & + & + \\
\hline Search, marketing & + & + & + & + & + \\
\hline Data import & Excel & Excel & Excel & Excel & Excel, Word \\
\hline Online support & + & + & + & + & + \\
\hline CMS availability & + & - & - & - & - \\
\hline System transparency & - & - & - & + & - \\
\hline B2B services & + & + & + & + & + \\
\hline \begin{tabular}{|l} 
Storage of data and history of \\
interrelations with customers
\end{tabular} & $\begin{array}{l}\text { Cloud }+ \\
\text { Relational } \\
\text { database }\end{array}$ & $\begin{array}{l}\text { Relational } \\
\text { database }\end{array}$ & \begin{tabular}{|l|}
\multicolumn{1}{|c|}{ SQL and } \\
NoSQL \\
databases
\end{tabular} & $\begin{array}{l}\text { Relational } \\
\text { database }\end{array}$ & $\begin{array}{l}\text { SQL, NoSQL database, } \\
\text { Azure Storage }\end{array}$ \\
\hline Monitoring manager's operation & + & + & + & + & + \\
\hline Reduction of transaction time & + & + & + & - & + \\
\hline Automation of business processes & + & + & + & + & + \\
\hline Telephony & + & + & + & + & + \\
\hline Cross-platform software & + & + & & & \\
\hline \begin{tabular}{|l} 
Integration with social networks, \\
Telegram and other messengers
\end{tabular} & + & + & + & - & + \\
\hline
\end{tabular}

Note: on the basis of expert survey; * - percent of expert references

\section{DISCUSSION}

Let us discuss in more details capabilities and opportunities of communications with consumers of the considered cloud-based CRM systems.

Bitrix24. Bitrix24 is not an open source system (though, free version is available with $5 \mathrm{~Gb}$ of cloud space), however, its advantage is in own cloud for file hosting, but customer information is stored in relational database.

The system provides opportunities of video communications, emailing, surveys, integration with
OneDrive, Google Drive, Dropbox; Microsoft Office document editing, search in documents, calendar, Android and IOS mobile clients, connection of external mail services, implementation of tasks, and others.

The system has user-friendly interface. Registration is sufficiently quick and can be performed using external services, for instance, Google. The following sections are presented on the main page: activity stream, tasks, chat and calls, groups, calendar, disk, mail, CRM, company, time and reports, sites, applications, CRM marketing, and others. 
The Activity stream presents widgets with announcements, tasks, and popular sections. The Tasks section demonstrates service of customer listing from database and scheduling interactions with, as well as data filtering. The Groups section demonstrates opportunity to create group and its search. Another services are Calendar: to plan any event, Disk: to save data; Mail: with integration of top mailing providers.

The highest interest is attracted to CRM section with subsection Start: showing work flows of managers and communication dynamics. The Lead subsection presents Kanban methodology and calendar with clocks. The Agreement subsection demonstrates stages of deals, preparation of documents, invoices for advanced payments, payments in progress, and final invoice. The Invoices and Proposals subsections are subdivided into two parts: new and sent to customer. The Reports subsection presents reports about transactions, commodities, leads, invoices, etc.

The Companies section allows to present graphically company structure with opportunity to add employee and department. Time and Report sections allow to develop absence chart, working time, working summary, working reports and meetings; manager's activity is monitored.

The Sites section runs in beta mode: it allows to develop a company site using existing templates, integration of CMS system into the site, this has not been used previously. CRM marketing is available with emailing services, SMS, messenger and information about calls. In addition, the system includes telephony services and profiles tuning.

Bitrix 24 allows to reduce deal time with customer, it can acquire complete analytical data and arrange reports, it provides automation of business processes and allows to record phone conversions for subsequent analysis. An obvious advantage is complete integration into social networks and messengers, in particular, it should be mentioned that the system is similar to a social network and enables comments and evaluations by employees.

AmoCRM. The main concept of this CRM system is the service of communications with customer, that is, each operator switched to amoCRM sends request to a potential customer from contractors, asks whether the customer is interested in this or that service, and then, depending on the customer choice, the conversation is analyzed by experts. AmoCRM is not an open source software, this is completely commercial product.

File hosting is based on relational database. It allows to reduce deal time upon interaction with customer. It is not cloud-based for file storage. B2B services and automation of business processes are available. It saves information and history of communications with customers. The system provides well-structured telephony and recording of phone conversations. It can be integrated into social networks and messengers.

AmoCRM is a cloud-based system, it is comprised of such main modules as desktop, deals, tasks, lists, analytics, and settings. The Desktop contains such subsections as sales, cold call, partners, task statistics, last events, search. The Deals section, as the Desktop, contains Sales, Cold call, Partners subsections. The Deals are presented in real time and classified according to current stages from negotiation start to completion. The Lists section contains separate subsections for contacts, companies, licenses, commodities, and services. The Analytics section provides information for company authorities, including statistics for duration, amount, efficiency of deals, completed and noncompleted agreements, cold calls, etc.

The system provides complete monitoring of managers, analyzes efficiency of their activities, and evaluates their actions. It is possible to review all managers, their statistics and list of deals.

Therefore, this CRM system is sufficiently attractive, it applies innovative methods relating to interactions with customer.

Terrasoft. This Russian company is one of the main producers of CRM systems. Its main product is BMP-online platform, combining numerous CRM solutions. Flexibility and scaling up of the platform allow to use it for development of own CRM solutions, to adjust and to tune the system in accordance with specificity of industry and features of certain company. Wide line of CRM solutions is available: management of sales of any type, automation of company marketing, arrangement of efficient customer servicing, simulation of business processes.

The Terrasoft CRM system provides opportunity to develop unified customer database, maintaining contacts, purchasing history, customer preferences, without data redundancy. Unfortunately, cloud services are not provided, though, B2B services are available. The system allows to save history of communication with customers and to analyze these data, thus decreasing the deal cycle. The Terrasoft system allows to automate business processes with generation of clear notations to users during simulation.

This system supports telephony with conversation recording, integration with external services and social networks is available, interaction with Excel, the interface is sufficiently user friendly. The system provides monitoring of manager's activities with their evaluation, as well as all basic services for communication with customer, the relevant information is stored using SQL and NoSQL databases.

According to expert opinion, the advantage of Terrasoft is opportunity to be tuned to company needs without involvement of qualified experts. The Terrasoft products are supported by all popular DBSM and propose solutions based on SaaS (software as a service) and Open Source basis. These systems are oriented both on industrial and trading companies. The level of developments allows to arrange remote working places, to improve operation efficiency of all employees. 
SugarCRM. It is a CRM system not based on recent innovative technologies, however, providing numerous services to plan sales, to automate marketing, lead management, sales automation. This system is used by such companies as Coca-Cola, IBM, Chevrolet. CRM provides support for companies with personnel from 1-9 to more than 2,000 employees. It operates with Android and IOS mobile clients, which provides certain advantages for customers. The interface is simple and intuitive, similar to Microsoft Office 98.

The CRM system allows to manage sales stages, such as marketing planning, previous contact, negotiations, agreements. The system is subdivided into modules and submodules. The main modules are events, contacts, contractors, preliminary contacts, deals, projects, requests, errors, documents, e-mail, and marketing.

The customer information is stored using relational database. Cloud-based service is unavailable. The system has B2B services, information about interrelations with customers. Manager's activities are monitored not in all versions. Decrease in time for deal is not stipulated, since only complete cycle is performed. Automation of business processes and telephony service are available due to integration of services from Intelco. Conversation recording is unavailable, it is provided only in customized versions, the system doesn't provide integration with social networks and messengers.

Therefore, the experts did not reveal any innovation approaches in this CRM, however, it is sufficiently user friendly and convenient. However, the experts believe that the main advantage is that SugarCRM is an open source software, which can be modified independently according to customer requirements. Basic version (free software) allows to study the capabilities of SugarCRM and to implement it further, module by module, without interruption of routine working cycle and existing business flowcharts. Remote access is advantageous: possibility to use the system by any browser being anywhere in the world, 24 hours a day.

Dynamics CRM. According to the expert opinion, the Microsoft CRM system is sufficiently innovative, it applies the most advanced techniques, though, it is not free. This CRM system executes all functions, which should be in a CRM system, due to implementation of new services and opportunities of Microsoft, especially Skype and Microsoft Azure.

Dynamics CRM is a commercial product, information is stored using SQL, NoSQL databases and Azure Storage. The system is sufficiently simple and is the fastest system among the previously discussed CRM solutions. Regular updates and expansion of functions are available, as well as maximum user-friendly interface. The system provides integration with all programs of Microsoft Office and other external services due to hosting on Microsoft Azure. Cloud is available due to integration with One Drive, B2B services, as well as opportunity to automate all business processes with demonstration in Workflow.

According to the expert opinion, Dynamics CRM covers wide range of business tasks: interaction with customers, complete analytics, monitoring, storage of all information and history of communications with customers. The system allows to monitor manager's activity at all stages of life cycle of communications with customers, the deal cycle can be reduced, if required, analytical data are acquired with appropriate reports; telephony service is provided, in particular, integration with Skype; phone conversations can be recorded for subsequent analysis; integration with social networks and messengers is available.

\section{CONCLUSION}

The following conclusions can be arrived at:

Cloud technologies play an important role in provision of operation and management of companies and are advantageous for ordinary customers, reducing licensing fees, providing free space for file storage and access to the files anywhere together with the opportunity to use various software and applications.

Modern CRM decisions, capabilities of CRM systems and technologies used by each CRM system were analyzed on the basis of expert survey. The expert survey has demonstrated that implementation of CRM system is one of prioritized areas of development of any company, since it can improve quality of customer services, decrease labor consumptions for maintenance, and eliminate routine activities.

Therefore, the obtained results have confirmed the hypothesis that cloud-based CRM system provides automation of interaction with customer and processing of customer requests, which positively impacts implementation of customer-oriented strategy and promotes increase in company profits.

\section{ACKNOWLEDGEMENT}

This work was supported by the Ministry of Science and Higher Education of the Russian Federation, project № FSSW2020-0010 titled Structural changes in economy and society as a result of achieving the target indicators of National projects, which provide opportunities to organize new areas of social and economic activity, including commercial, both in Russia and abroad.

\section{REFERENCES}

1. E.B. Shtukareva, S. Sergeeva, Y. Zolotukhina, A. Orlyuk, I.A. Kopylov. Internet Communications in the Context of Restrictions on Population Mobility. International Journal of Advanced Trends in Computer Science and Engineering, vol. 9, no. 3, pp. 3904 - 3909, 2020.

https://doi.org/10.30534/ijatcse/2020/211932020 
2. L. Simonova, E. Egorova, A. Akhmadiev. Knowledge Acquisition for Engineering Decisions Based on Functional Relationships. International Journal of Emerging Trends in Engineering Research, vol. 8, no. 6, pp. 2774- 2778, 2020.

3. D.G. Korneev, M.S. Gasparian, A.A. Mikryukov, E.V. Yaroshenko, G.E. Golkina. The Technology for Semantic Interoperability based on a Cognitive Approach. International Journal of Advanced Trends in Computer Science and Engineering, vol. 9, no. 3, pp. 3637 - 3640, 2020.

https://doi.org/10.30534/ijatcse/2020/172932020

4. A.A. Fedulin, I.V. Chernaya, E.Y. Orlova, G.I. Avtsinova, T.V. Simonyan. Formation of Approaches to Environmental Policy under Conditions of Digital Economy. Journal of Environmental Management and Tourism, vol. 11, no. 3, pp. 549-554, 2020.

5. P. Guenzi, K. Storbacka. The organizational implications of implementing key account management: A case-based examination. Industrial Marketing Management, vol. 45, pp. 84-97, 2016.

6. A.S. Troshin, A.P. Sokolova, E.O. Ermolaeva, R.M. Magomedov, T.L. Fomicheva. Information Technology in Tourism: Effective Strategies for Communication with Consumers. Journal of Environmental Management and Tourism, vol. 11, no. 2, pp. 322-330, 2020.

7. A. Baltabayeva, A. Bekmetova, B. Kylyshpayeva, Z. Assanova, G. Zhunussova. Environmentally Oriented Anti-Crisis Management of Enterprises: Problems, Directions, and Prospects. Journal of Environmental Management and Tourism, vol. 11, no. 1, pp. 131-138, 2020.

8. I.J. Chen, K. Popovich. Understanding customer relationship management (CRM): People, process and technology. Business Process Management Journal, vol. 9, no. 5, pp. 672-688, 2003. https://doi.org/10.1108/14637150310496758

9. T. Coltman, T.M. Devinnery, D.F. Midgley. Customer relationship management and firm performance. Journal of Information Technology, vol. 26, pp. 205-219, 2011.

10. M. Batter. The impact of customer relationship management capability on innovation and performance advantages: testing a mediated model. Journal of Marketing Management, vol. 26, no. 9-10, pp. 842-857, 2010.

11. A.V. Ryzhik, V.L. Slesarev, V.A. Malcev, V.P. Kamishansky. Website as an e-Commerce Tool: Regulatory Technology. Journal of Advanced Research in Law and Economics, vol. 11, no. 3, pp. 1032 - 1038, 2020.

12. L. Kopteva, I. Romanova. Digitalization as a Condition for Developing Agriculture and Ensuring Food Security of the Country. Journal of Advanced Research in Law and Economics, vol. 10, no. 6, pp. 1898-1906, 2019.
13. E.A. Smirnova, E.I. Kuznetsova, D.V. Dianov, O.M. Tolmachev. Application of crm-systems in the work of retail franchise networks. Revista Inclusiones, vol. 7, no. Especial, pp. 590-601, 2020.

14. D.M. Lambert. Customer relationship management as a business process. Journal of Business \& Industrial Marketing, vol. 25, no. 1, pp. 4-17, 2010. https://doi.org/10.1108/08858621011009119

15. J. Dyché. The CRM Handbook: A Business Guide to Customer Relationship Management. Boston: Addison Wesley, 2002.

16. D. Finnegan, L.P. Willcocks. Implementing CRM: From Technology to Knowledge. Chichester: Willey, 2007.

17. C.S. Long, R. halafinezhad, W.K.W. Ismail, S.Z.A. Rasid. Impact of CRM Factors on Customer Satisfaction and Loyalty. Procedia Economics and Finance, vol. 23, pp. 563-567, 2015.

18. M. Gibbert, M. Leibold, G. Probst. Five styles of customer knowledge management, and how smart companies use them to create value. European Management Journal, vol. 20, pp. 459-469, 2002.

19. R.S. Boulding, W.M. Ehret, W.J. Johnston. A Customer Relationship Management Roadmap: What Is Known, Potential Pitfalls, and Where to Go. Journal of Marketing, vol. 69, pp. 155-166, 2005.

20. Ga.A. Elnikova, Y.A. Laamarti, G.S. Zhukova, G. Boykova, A.A. Gorbunov. Educational orientations of provincial youth. Revista Inclusiones, vol. 7, no. Especial, pp. 274- 289, 2020

21. X. Yurong, C. David, L. Binshan, C. David. Adopting customer relationship management technology. Industrial Management \& Data Systems, vol. 102, no. 8, pp. 442-452, 2002.

22. N.H. Thuy Uyen, J.S. Sherif, M. Newby. Strategies for Successful CRM Implementation. Information Management \& Computer Security, vol. 15, pp. 102-115, 2007.

23. H.-S. Kim, Y.-G. Kim. A CRM performance measurement framework: Its development process and application. Industrial Marketing Management, vol. 38, pp. 447-489, 2009.

24. K.A. Richards, E. Jones. Customer relationship management: Finding value drivers. Industrial Marketing Management, vol. 37, no. 2, pp. 120-130, 2008.

25. R. Bose. Customer relationship management: key components for IT success. Industrial Management and Data Systems, vol. 102, pp. 89-97, 2002.

26. S. Marston, L. Zhi, S. Bandyopadhyay, J. Zhang, A. Ghalsasi. Cloud Computing: The Business Perspective. Decision Support Systems, vol. 51, pp. 176-189, 2011. https://doi.org/10.1016/j.dss.2010.12.006

27. Q. Zhang, L. Cheng, R. Boutaba. Cloud computing: state-of-the art and research challenges. Journal of 
Internet Services and Applications, vol. 1, pp. 7-18, 2010.

28. S.J. Berman, L. Kesterson-Townes, A. Marshall, R. Srivathsa. How cloud computing enables process and business model innovation. Strategy \& Leadership, vol. 40, no. 4, pp. 27-35, 2012.

29. S.N. Gambhire, A.P. Gavhane, M. Patil. Power of cloud computing in customer relationship management. International Journal of Management, vol. 3, no. 1, pp. 225-230, 2012.

30. M.D. Ahearne, D.E. Hughes, N. Schillewaert. Why sales reps should welcome information technology: Measuring the impact of CRM-based IT on sales effectiveness. International Journal of Research in Marketing, vol. 24, pp. 336-349, 2007.

https://doi.org/10.1016/j.ijresmar.2007.09.003 